\title{
The Effect of the ECB's Forward Guidance on Interest Rate Forecasts
}

\author{
Ralf Fendel $^{1}$, Jan Heins ${ }^{1} \&$ Oliver Mohr ${ }^{1,2}$ \\ ${ }^{1}$ WHU - Otto Beisheim School of Management, Vallendar, Germany \\ ${ }^{2}$ PIMCO, Germany \\ Correspondence: Ralf Fendel, WHU - Otto Beisheim School of Management, Burgplatz 2, 56179 Vallendar, \\ Germany. Tel: 49-261-6509-290. E-mail: Ralf.Fendel@whu.edu
}

Received: April 15, 2020

Accepted: June 7, 2020

Online Published: June 28, 2020

doi:10.5539/ijef.v12n8p52

URL: https://doi.org/10.5539/ijef.v12n8p52

The views expressed in this paper are those of the authors and do not constitute official PIMCO views.

\begin{abstract}
This study analyzes the impact of forward guidance (FG) by the ECB on the forecast error of financial markets participants regarding the interest rate level and the slope of the yield curve. We refer to OIS (overnight index swap) forwards as the relevant forecasts and purge the prediction error of several macroeconomic and financial variables to gain a pure representation of the exogenous forecast error. To isolate the effect of FG, this study refers to the absolute deviation of forecasts from actual rates and further controls for variables representing unconventional monetary policies. We find that the introduction of FG improved interest rate predictability for shorter maturities while the substantial decline of long-term interest rates has caught markets by surprise. Hence, the ECB's intended reduction of refinancing rates at the longer end of the interest rate curve came at the cost of lower predictability of the slope of the yield curve.
\end{abstract}

Keywords: forward guidance, Eurozone, zero lower bound, interest rate forecasts, ECB

\section{Introduction}

Not only since the beginning of the prolonged low-interest rate environment have central banks been carefully shaping their communication policy to influence public expectations on the future path of monetary policy. Within the existing monetary policy framework, statements have ranged from the assessment of future economic conditions which implicitly convey future policies to the explicit announcement of future monetary policy. Already in 1997, the Reserve Bank of New Zealand has started to publish an interest rate forecast, which was soon adopted by the Norges Bank and the Sveriges Riskbank. In contrast to this purely qualitative communication strategy, the current connotation of forward guidance (FG) is of more quantitative and exogenous character.

The main driver for the emergence of the current form of FG has been the need to steer markets expectations at the zero lower bound (ZLB). First, the effectiveness of changing the short-term policy rate has been impaired by its downward rigidity. Hence, gaining control of the medium and longer part of the interest rate curve becomes more imminent. Second, deflationary concerns have been increasingly present with a higher need to anchor medium-term inflation expectations given less room at the ZLB. Third, market participants have faced higher uncertainty in predicting monetary policy as central banking at the ZLB for a long period of time is unprecedented in history.

In fact, statements of the likely interest rate path can be broadly categorized into three groups along following dimensions: (i) Prospects of economic conditions, (ii) the achievement of policy goals, and (iii) a time component. The first category of FG makes the future path of monetary policy contingent on the future macroeconomic environment (Note 1). Hence, a central bank still maintains some degree of flexibility to change course in case economic realities are shifting without risking their credibility. At the same time, this communication policy provides markets with some degree of assurance. The second category of FG relates to reaching mandated policy goals such as the inflation rate, economic growth or unemployment rates (Note 2). This type of FG represents an extension of the first category, as it relates to the goal variables that are ultimately influenced by economic conditions. However, it is more explicit by making future monetary policy accountable 
in reaching stated policy goals. Even though it carries a higher degree of commitment, economic agents are aware of the limitations of a central bank in their ability to influence economic transmission channels. Hence, the possibility of changing monetary actions and corresponding uncertainty remains. The third category attaches a particular date to the duration of FG (Note 3). Under this communication strategy, a central bank deliberately limits its flexibility to react to changing circumstances for a certain period of time. From a theoretical perspective, it should provide markets with the highest degree of confidence in future monetary policy. Against the background of the diverse nature of FG, this study applies a parsimonious definition of FG and refers to the official starting date as suggested by the ECB itself.

This study analyzes the impact of the ECB's FG on the forecast error of financial markets participants regarding the interest rate level and the slope of the yield curve for the period from Q1/2010 to Q4/2018. We refer to overnight index (OIS) forward rates as the relevant forecasts and purge the prediction error of several macroeconomic and financial variables to gain a pure representation of the exogenous forecast error. To quantify and isolate the effect of FG, we refer to the absolute deviation of forecasts from actual rates and further control for variables representing unconventional monetary policies.

The paper is structured as follows: The second section reviews and classifies the nature of the ECB's FG including a literature review on interest rate predictability. The third section covers the methodology and data sources. The fourth section entails the results with subsequent robustness tests in section five. Section six concludes.

\section{The ECB's Forward Guidance}

According to the ECB itself, July $4^{\text {th }} 2013$ marks the official introduction of FG to the European currency area (ECB, 2014). On that day, the ECB Governing Council in person of its president Mario Draghi assured financial markets that key interest rates are expected to "remain at present or lower levels for an extended period of time" (Draghi, 2013). This type of FG borrows elements of the third category by introducing a weak time commitment. The communication policy of the ECB also added a goal-specific component by referring to "the overall subdued outlook for inflation extending into the medium term" during the introductory statement of the press conference. Although the Governing Council has long before commented on anchoring inflation expectations, the ECB became more explicit during the period of unconventional monetary policy in referencing to observable market rates such as the 5y5y break-even inflation rate as a gauge for price stability. In addition, the ECB continued to provide their assessment of various economic parameters such as the "high degree of unutilized capacity, and subdued money and credit creation" (Draghi, 2014).

Hence, the type of FG adopted by the ECB has emerged as a combination of the three different categories: A mild date-based and goal-specific future monetary policy that is conditional on anchoring of inflation expectations. While July $4^{\text {th }}, 2013$ represents the ECB's self-proclaimed start of FG, the debate of the actual (i.e., de facto) start of this new form of communication policy remains ambiguous. At the height of the European peripheral sovereign debt crisis in June 2012 when markets where testing the possibility of currency redenomination of southern European countries, Mario Draghi held the infamous speech in London reassuring the currency area that the ECB will "do whatever it takes" (Mario, 2012) to preserve the euro within the ECB's mandate. Although it was less specific in its future actions, it was not less significant in its importance. Hence, the subsequent analysis will leave some room for a revised period of FG.

\subsection{Transmission Channels of Forward Guidance}

The theoretical foundations of FG suggest three transmission channels. First, FG increases the control of central banks over medium to longer dated maturities on the yield curve. A central bank gains stronger influence on the parts of the yield curve that are further out the maturity spectrum by committing to a certain policy path of future short-term policy rates. Both consumers and corporations will be affected through the refinancing channel exerting a direct influence on consumption, housing, and investments. From an empirical perspective, this channel should manifest itself in a stronger flattening of the yield curve as compared to previous phases of expansionary monetary policy based on 'traditional' interest rate policy. A second channel relies on higher credibility of policy objectives which should help anchoring expectations. Particularly at the ZLB, the public testimony of sustained lower rates provides the central bank with an additional tool to address deflationary tendencies. A third channel is higher predictability of future interest rate which compresses the term premium. By reducing the probability of monetary policy surprises, FG could lower volatility of financial market interest rates and decrease uncertainty among corporations with respect to refinancing conditions. Hence, this transmission channel should lower the responsiveness of financial markets to monetary policy announcements and stabilize lending conditions for the real economy. 
Becker and Smith (2015) provide a general assessment of above-mentioned transmission channels and find that FG at the ZLB has a positive and significant positive effect on US employment and the price level. To compare this communication tool to conventional interest rate cuts, the authors estimate a VAR for the period between 1979 and 2008 and a similar model for the period thereafter when the Fed started to engage in FG at the ZLB. Results indicate that FG needs to be larger in size than a regular rate cut to achieve similar results (with a ratio of 5 to 1). This is in line with the well-known FG puzzle (Del Negro et al., 2012), which points to the discrepancy between the theoretical view provided by DSGE models that FG is highly effective and more mixed empirical results.

In fact, one source of ambiguity stems from the nature of the announcement which Campbell et al. (2012) have classified into Odyssean or Delphic FG. The latter type of communication policy is of more implicit nature as it conveys expectations about future economic fundamentals. Thus, Delphic FG points to the likely policy response under a transparent and functioning policy framework. Odyssean FG, to the contrary, represents a firmer commitment to future monetary policy measures in response to unexpected economic developments that cannot be effectively addressed by conventional monetary policy. Under this particular regime, a central bank binds itself to promises of the past and increases its credibility at the cost of future flexibility. Andrade and Ferroni (2016) analyze the impact of ECB statements on inflation expectations and categorize the communication policy of the ECB over 15 years into a binary classification system (Odyssean vs. Delphic FG). The authors find that both types of communication policy co-existed, however, with different relative importance (Note 4). Since 2002, ECB policy has been dominated by the Delphic component, while Odyssean FG has become more relevant in later years. In our study, we focus on those later years of the Euro Area and the effects of FG on the third transmission channel - higher interest rate predictability and lower interest rate variability.

\subsection{Interest Rate Predictability under Forward Guidance}

The empirical literature on interest rate predictability under central bank communication often starts with the weak form of interest rate FG where policymakers publish the expected path of interest rates. Goodhart and Lim (2011) assess the quality of interest rate forecasts based on market implied rates for the UK (Libor rates and the government yield curve) and forecasts made by the Reserve Bank of New Zealand. To test for the unbiasedness hypothesis of forecasts, their analysis uses the Mincer-Zarnowitz regression (Mincer \& Zarnowitz, 1969) that considers the difference of interest rate forecast and the realized yield over different horizons including a modification that focuses solely on the deviation by removing the absolute yield level. Results indicate high forecasting quality for the next quarter and rapidly decreasing forecasting quality after 6 months. Hence, the authors suggest a hybrid forecast combining an educated guess for the short-term and the assumption of unchanged rates for the medium term.

Kool and Thornton (2015) throw the spotlight on the Reserve Bank of New Zealand, the Norges Bank, the Sveriges Riskbank and the Federal Reserve to estimate the effect of the communication policy on interest rate predictability. While FG guidance of the former three central banks is largely restricted to interest rate forecasts over the three-year horizon, the study defines two distinct periods of FG reflecting the change from a time-contingent to a state-contingent FG in December 2012. The authors define the prediction error as a loss function (Note 5) based on survey data of interest rate forecasts for the three and twelve-month horizon and examine the coefficient of a dummy variable reflecting FG. Results indicate a significant impact of FG for the RBNZ and limited support for FG efficiency for the other central banks. In a robustness check, the authors further include benchmark variables capturing the forecast error for countries whose central banks do not engage in FG and test against a random walk. Findings for New Zealand cannot be substantiated, however, there appears to be evidence that forecasters converge in the case of New Zealand.

Andersson and Hofmann (2009) use two types of benchmarks to compare the effectiveness of expected interest rate paths published by central banks: First, they compare central banks with FG to those with similar characteristics but different communication policies (RNBZ and Riksbank). Secondly, the authors analyze different regimes of the same central bank, comparing the period before and after the introduction of publishing the interest rate forecast (Norges Bank). Controlling for domestic and foreign economic news, the authors regress daily changes in forward rates on a target surprise and a path surprise variable. Results suggest that interest rate predictability does not increase further if central banks have already operated under transparent and credible goal variables. However, results for the Reserve Bank of New Zealand indicate higher control over the mid-part of the interest rate curve which responds stronger to the publication of the interest rate path than its benchmark (announcements made by the Riksbank).

Hubert and Labondance (2018) analyze the impact of ECB's FG on different OIS rates ranging from one month 
to ten years forward. The authors conduct a high-frequency event study based on different regression models (OLS, TARCH and GARCH) and include FG as a dummy variable. Differentiating further between different instances of FG, the study identifies three events, including July $4^{\text {th }} 2013$, January $9^{\text {th }} 2014$ and the announcement of QE on January $22^{\text {nd }} 2015$. The authors highlight that no other monetary policy decisions were communicated between the first two dates. To control for other monetary policy decisions taken, the authors account for monetary policy shocks including the shadow interest rate by Krippner (2013, 2014), a high-frequency method by Kuttner (2001) as well as a vector covering daily price fluctuations of the oil price, the EuroSTOXX 50 and the ESI. Results indicate that ECB's FG has a persistent effect across the whole term structure with an increasing impact further out on the curve, where OIS rates fall by 5 basis points at the three and five-year horizon following an FG announcement.

\section{Data and Methodology}

To quantify the impact of FG on interest rate predictability, the set-up of the study aims to ensure three properties. First, the forecasts need to be unbiased predictors of future interest rates. Second, the error term should be a representation of the exogenous mis-estimation of market participants and not the result of incoming information between the forecast and the observed interest rate. Third, the effect of FG needs to be separated from other tools of unconventional monetary policy. In the subsequent sections we describe our data handling and the Appendix provides some more details of the employed data series.

\subsection{Definition of the Error Term}

Regarding the predictor of interest rates, our analysis refers to market-based forward rates instead of survey forecasts. The main advantages of the market-based rate are higher availability of different maturities and higher frequency coupled with the economic relevance of the decision behind these estimates. We choose the overnight index swap (OIS) over the Euribor for mainly three reasons: First, the OIS is a secured contract between two financial market participants and has no counterparty credit risk, whereas Euribor rates incorporate a risk premium given their unsecured nature. While spread levels between both types of rates remain relatively constant for most of the periods, there have been sharp increases of the Euribor during times of distress due to additional risk factors (Schrimpf \& Sushko, 2019). Second, the OIS is a truly market-determined rate while the Euribor is determined by selected financial institutions (Note 6). Third, the LIBOR scandal (Note 7) gave rise to more trading activity in OIS, which increases the reliability and the significance of available data collections.

The sample includes daily data for the period between Q1 2010 to Q4 2018 available from Bloomberg. We define the prediction error term as follows:

$$
y_{\text {Level }}=O I S_{t 0, t 1, z}-i_{t 1, z}
$$

The level of the (one-year ahead) forecasting error, $y_{\text {Level }}$, is defined as the difference between the forward OIS rate at $\mathrm{t} 0$ with a maturity of $\mathrm{z}$ effective from time $\mathrm{t} 1$ and the observation of the actual (realized) interest rate at $\mathrm{t} 1$ for the same maturity $z$. In the baseline model, we cover the 1yr OIS forward for a maturity of 1 year. A positive error term indicates that the estimated interest rate turned out to be higher than the realized and vice versa. As a robustness test, we will further include the $1 \mathrm{yr}$ forecast for the $3 \mathrm{mth}$ and the $10 \mathrm{yr}$ maturities.

For the second perspective, the shape of the yield curve, we follow a similar logic:

$$
y_{\text {Curve }}=\left(O I S_{t 0, t 1, z 2}-O I S_{t 0, t 1, z 1}\right)-\left(i_{t 1, z 2}-i_{t 1, z 1}\right)
$$

The forecast of the slope is the difference between the forward OIS with the long maturity z2 and the forward OIS with the short maturity z1 (the first difference element in eq. (2)). This implicit slope is compared to the actual realization of the slope represented by the difference between the observed interest rates, $i$, of the maturities z2 and z1 at time t1 (second difference element in eq. (2)). This results in the one year ahead forecast error for the slope of the yield curve, $y_{\text {Curve }}$. Our baseline model looks at the difference between $(\mathrm{z} 2=) 10 \mathrm{yr}$ and $(\mathrm{z} 1=) 3 \mathrm{mth}$ maturities given its role as the most important indicator of the business cycle. A positive value of the forecast error indicates that markets expect the yield curve to be steeper than its actual later realization. Our robustness test extends this perspective to the sub-segments, the slope between the 1yr and $3 \mathrm{mth}$ maturity and the $10 \mathrm{yr}$ and the $3 \mathrm{mth}$ maturity.

\subsection{Purging the Error Term from External Influences}

As our intent is to measure the impact of FG on interest rate predictability, we purge the prediction error term from influences that are due to information that occurred between the date of the forecast and the actual realization of the interest rate one year ahead. We follow a procedure suggested by Hatzius et al. (2010) and estimate a regression with the forecast error as the dependent variable to purge it from a number of factors that could substantially affect the quality of the prediction. 
Our assumption is that the residual of this regression represents the prediction error which is uncorrelated to the updated information set. We regress

$$
y=\alpha+\sum_{i=1}^{n} \beta_{i} * v_{i}+\varepsilon
$$

where $y$ represents the prediction error of the interest rate level or curve as defined in the previous section in eqs (1) and (2), respectively. We include a constant, $\alpha$, which represents the term premium inherent in interest rate forecasts as well as the asymmetric nature of the future path of interest rates at the ZLB. The vector $v_{i}$ contains a number of variables that reflect macroeconomic dynamics, developments on financial markets and general risk sentiment. The regressors include the $1 \mathrm{yr}$ growth rates of real GDP and core inflation to capture fundamental developments in the economy that have an effect on central banks and market participants. The Bund-BTP spread represents the difference between the 10yr generic German government bond yield and the equivalent yield of government bonds of Italy to capture periods of financial market fragmentation within the euro area. In addition, we include the 1yr return of the EuroSTOXX50 as well as a risk vector, which combines various measures of volatility via principal component analysis (equity markets, interest rate volatility, commodities). The residual $\varepsilon$ is of our main focus and represents our purged forecast prediction error which serves as the basis for the subsequent steps.

\subsection{Definition of Forward Guidance}

The third step of the analysis assesses the impact of central bank policy on the purged forecast error. To quantify the impact, we look at the absolute error term and estimate a regression containing a dummy variable that takes the value of 1 since the official introduction of FG on April $4^{\text {th }}$, 2013. To distinguish between FG and additional monetary policy tools, we further include four control variables, which represent the level of different monetary operations the ECB conducted over this time period.

$$
y_{\text {purged }}=\alpha+\sum_{i=1}^{n} \beta_{i} * F G_{i}+\sum_{i=1}^{n} \gamma_{i} *\left[\begin{array}{c}
\text { LTRO } \\
\text { TLTRO } \\
\text { EAPP } \\
\text { ExCLiq }
\end{array}\right]_{i}+\varepsilon
$$

FG represents the dummy variable taking the value of 1 or 0 . The control vector contains four variables (Note 8): First, the ECB Balance Sheet Long Term Refinancing Operations (LTRO) was designed to ease refinancing problems of peripheral countries during the height of the European peripheral crisis under strict conditionality. Second, the Targeted Longer-Term Refinancing Operations (TLTROs) were introduced to revive credit growth and help the economy to escape the liquidity trap. Third, the Expanded Asset Purchases programme (EAPP) was a broad-based attempt to revive different monetary transmission channels through lowering refinancing conditions across different markets. In addition, we included an aggregate measure of excess liquidity (ExcLiq) in the market as the fourth control variable as the ECB has been lending unlimited amounts of liquidity to banks in response to the financial crisis. Given the ambiguity of the start of FG, the analysis tests for an additional potential starting date in the robustness section. On July $26^{\text {th }} 2012$, Mario Draghi affirmed markets that the ECB "will do whatever it takes" to preserve the euro, which represent a holistic form of FG covering not only interest rates but the full plethora of central bank tools (Draghi, 2012).

\section{Results}

This section decomposes the prediction error of interest rates and the yield curve stepwise from the observable to the unobservable components. In a first step, we provide a qualitative description of the observable forecast error over the sample period. In a subsequent step, we account for the incomplete set of information that financial market participants have at the time of making the prediction. We purge the original error term of macroeconomic and financial information coming in between the date of the forecast and the actual realization as described above. In a third step, we quantify the effect of forward guidance on forecast accuracy while controlling for other monetary policy actions.

\subsection{The Observable Forecast Error}

The traditional (i.e., representative) interest rate path during an economic expansion can be described by incremental increases of the short-term interest rate followed by a pause during the more advanced stages of the economic cycle. Subsequently, a faster decrease of interest rates towards the ZLB reverses the upward trend as economic conditions begin to deteriorate. In the aftermath of an economic downturn, interest rates remain at lower levels until the central bank tends to initiate the lift-off when data suggests sufficient confidence in the economy.

The sample period of this study, however, does not exhibit these traditional dynamics of an economic recovery. 
The period under consideration can be categorized into different sub-periods beginning with an initial recovery phase in the aftermath of the Global Financial Crisis (GFC). As an economic recession and a financial crisis coincided, the extent of the GDP shortfall during the GFC was larger than in previous recessions and it took the ECB about three years to pursue two interest rate hikes in 2011. This provided the monetary prelude to the double-dip recession that hit the Eurozone in 2012 with a regional focus in the European periphery. The ECB responded with a reversal of monetary policy, and steered rates towards the ZLB for the remainder of the sample period to stimulate economic activity in the wake of a liquidity trap. In the following period, the euro area experienced sluggish economic growth dynamics between 2013 until 2016 with a temporary pick-up of credit growth and investment in 2017. Despite a gradual normalization of economic activity, monetary policy did not return to the traditional interest rate path but referred to a variety of unconventional monetary measures.

The forecast error term of the interest rate level for $1 \mathrm{yr}$ maturities of the OIS contract one year into the future picks up the economic volatility in the first half of the sample period and yields a consistent positive term premium (see Figure 1).

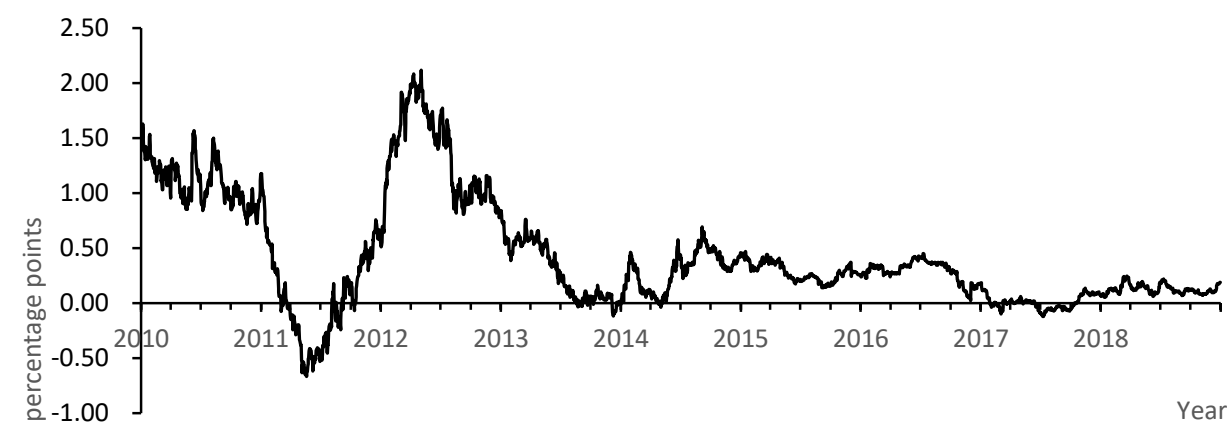

Figure 1. One year into one year forecasting error

During the first period in the immediate aftermath of the GFC, markets have overestimated the pace of interest rate normalization by the central bank. When the ECB decided to hike rates twice in 2011, the error term eventually disappeared for a couple of months until the European peripheral sovereign debt crisis unfolded. Following the reversal of the hawkish mistake by the central bank and subsequent interest rates cuts, the market finally began to price in a lower trajectory of future interest rate policy. The average forecasting error for the period between Q1 2013 and Q4 2017 drops down to 0.22pp from 0.69pp in the earlier period. The observation of a consistent term premium displayed by the positive error term can be explained by the asymmetric nature of the future trajectory at the ZLB. While room for further interest rate compression is limited, it is rational for markets to price in a certain probability that the ECB may reverse course. Goodhart and Lim (2011) show that interest rate forecasts are biased due to the state of the business cycle. Once a central bank has started hiking interest rates during a recovery, markets underestimate the pace of rate increases while the reverse holds true for an economic contraction in a falling interest rate environment. A possible explanation could be that turning points in interest rate policy are inherently difficult to predict. During the last decade, financial markets were pricing in the potential start of the rate hike cycle as a tail-event through the persistent term premium.

Regarding the market's forecasting ability on the slope of the interest rate curve, our analysis focuses on the difference between interest rates of $10 \mathrm{yr}$ and $3 \mathrm{mth}$ maturities one year ahead (see Figure 2).

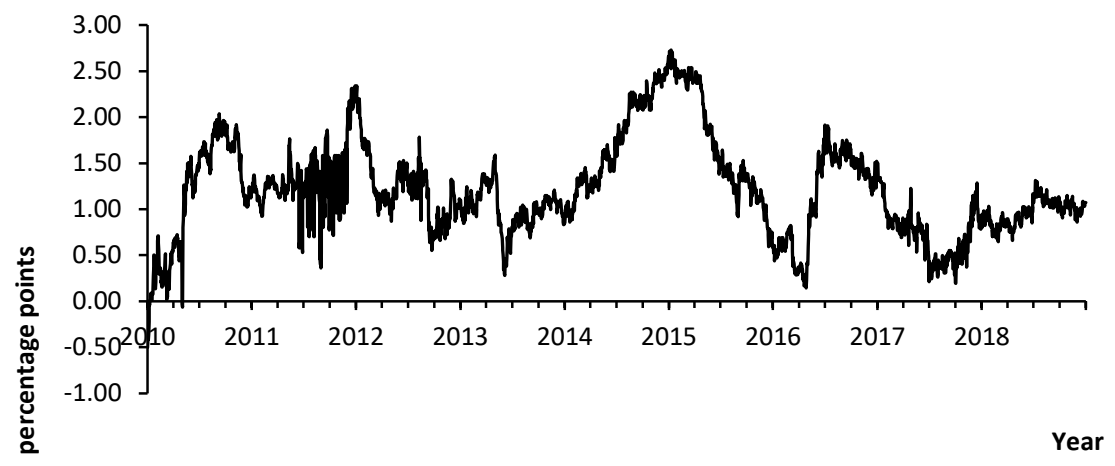

Figure 2. Ten year into three month forecasting error 
Over almost the entire sample period, markets have constantly overestimated the steepness of the curve by $1.21 \mathrm{pp}$ on average. While the error term over the first four years remains rather range-bound after surging from negative territory in the first quarter in 2010, we can observe a global maximum of the error term during the period between Q3 2014 and Q2 2015 (2.72pp) and a local maximum between Q3 and Q4 2016 (1.91pp), where markets significantly overestimated the slope of the curve. This observation stands in contrast to the previous analysis on the forecast error of the interest rate level, where the error term dropped during the later years. When decomposing the drivers of this structural, positive deviation of the curve forecast, data indicates that markets have not correctly estimated the structural decline of the 10yr interest rate. From Q2 2012 onwards, the 10yr maturity declined from levels around $2.5 \%$ to an absolute low in Q2 2017 of $0.86 \%$. For a brief period at the beginning in 2015 , both forecasts and actual rates had been aligned. This was driven by recessionary fears earlier that year which translated into a flattening of yield curve expectations. As concerns about future economic growth turned out to be overstated, the 10yr rate increased in the second half of 2015, which reduced the positive forecast error. The observations for the sample period underline that markets were surprised by the flattening of the interest rate curve over the last 4 years.

\subsection{Assessment of the Exogeneous Prediction Error}

To extract the exogenous component of the forecast error unrelated to the business cycle, we regress the forecast error on a vector containing information about the real economy, financial market data and risk sentiment as shown in eq. (3). We interpret the error term of the regression as the purified prediction error. Results for the level forecasts suggest that all regressors are highly significant and explain 58\% of the variation of the purged error term (see Table 1).

Table 1. Regression results of Eq. (3) - Purging the level forecast error

\begin{tabular}{lcccccc}
\hline & coef & std err & $\mathrm{t}$ & $\mathrm{P}>|\mathrm{t}|$ & {$[0.025$} & $0.975]$ \\
\hline const & 1.0338 & 0.027 & 38.969 & 0.000 & 0.982 \\
Real GDP yoy sa & -0.2961 & 0.519 & -57.061 & 0.000 & -0.3063 \\
Inflation yoy sa & -0.2068 & 1.904 & -10.865 & 0.000 & -0.2441 \\
Equity Markets yoy & -0.7884 & 0.055 & -14.267 & 0.000 & -0.897 \\
Vector Risk yoy & -0.1036 & 0.008 & -12.406 & 0.000 & -0.120 \\
BTP yoy & 0.2080 & 0.006 & 35.251 & 0.000 & 0.196 \\
Dep. Variable: & FE 1Y & R-squared: & 0.584 & & -0.087 \\
Model: & OLS & Adj. R-squared: & 0.584 & & 0.220 \\
No. Observations: & 3287 & AIC: & BIC: & 1881. & & 1918. \\
Df Residuals: & 3281 & & &
\end{tabular}

The variables that describe a sizeable portion of the observed variation are real GDP, core inflation and the Bund-BTP spread. The coefficients for the year-on-year growth of (seasonally adjusted) real GDP and (seasonally adjusted) core inflation are negative, which associates an increase of these variables with a negative forecast error. Hence, positive GDP data and increasing inflation push up actual rates beyond what was expected at the time of the $1 \mathrm{yr}$ ahead forecast. While 1pp GDP growth has an impact of $-0.3 \mathrm{pp}$ on the forecast error, $1 \mathrm{pp}$ of inflation growth exerts downward pressure of $-0.21 \mathrm{pp}$. Results reveal a positive coefficient for the $1 \mathrm{yr}$ change of the Bund-BTP spread, indicating that a widening of the perceived risk difference between 10yr German and Italian government bonds coincides with an overshooting of rates expectations. As fears about the European periphery were emerging, the absolute level of rates in the Eurozone declined leading to a positive forecast error of $0.2 \mathrm{pp}$ for a $1 \mathrm{pp}$ Bund-BTP spread. The coefficients for the equity and the risk vector are also significant. This underlines that yield forecasts respond to both fundamental economic data and risks concerning the unity of the currency bloc, but also equity markets or general risk sentiment. The intercept of the regression stands at 1.03pp which we interpret as the sum of the term premium and the asymmetric risk of an increase in rates at the ZLB when controlling for the impact of the business cycle on the forecast error. The purified prediction error displayed in Figure 3 has a correlation of 0.64 with the original time series. The dominant impact of the business cycle on the raw forecast error term is largely eliminated. 


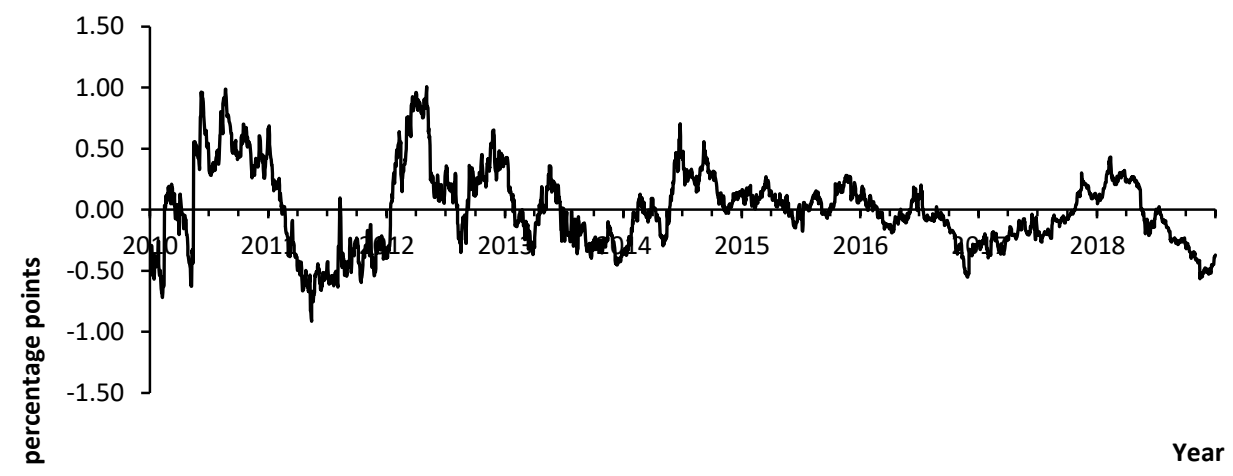

Figure 3. Macro purged level error

Regression results for eq. (3] using the yield curve forecast displayed in Table 2 show that regressors are significant except for the Bund-BTP spread (only significant at the $10 \%$ level). The amount of variation that is explained by economic and financial data decreases to $14 \%$.

Table 2. Regression results of Eq. (3) - Purging the yield curve forecast error

\begin{tabular}{|c|c|c|c|c|c|c|}
\hline & coef & std err & $\mathrm{t}$ & $\mathrm{P}>|\mathrm{t}|$ & {$[0.025$} & $0.975]$ \\
\hline const & 1.6694 & 0.041 & 41.160 & 0.000 & 1.590 & 1.749 \\
\hline Real GDP yoy sa & 0.0392 & 0.793 & 4.948 & 0.000 & 0.0237 & 0.0548 \\
\hline Inflation yoy sa & -0.4143 & 2.910 & -14.239 & 0.000 & -0.4714 & -0.3573 \\
\hline Equity Markets yoy & -0.5059 & 0.084 & -5.988 & 0.000 & -0.672 & -0.340 \\
\hline Vector Risk yoy & 0.1104 & 0.013 & 8.653 & 0.000 & 0.085 & 0.135 \\
\hline BTP yoy & 0.0155 & 0.009 & 1.718 & 0.000 & -0.002 & 0.033 \\
\hline Dep. Variable: & FE $3 \mathrm{M} 10 \mathrm{Y}$ & R-squared: & 0.144 & & & \\
\hline Model: & OLS & Adj. R-squared: & 0.142 & & & \\
\hline No. Observations: & 3287 & AIC: & 4698. & & & \\
\hline Df Residuals: & 3281 & BIC: & 4735. & & & \\
\hline
\end{tabular}

In line with the analysis of the level forecast error, real GDP and core inflation are the variables that are driving the prediction error. However, the signs of their coefficients are different with real GDP being associated with a positive forecast error and core inflation leading to a lower and in absolute terms much larger forecast error. An increase of core inflation by $1 \mathrm{pp}$ is decreasing the prediction error by $0.41 \mathrm{pp}$ as the actual curve becomes steeper and closer to what was anticipated. Inflation exerts a stronger impact on $10 \mathrm{yr}$ rates yielding a prediction error of $-0.61 \mathrm{pp}$ as compared to $-0.27 \mathrm{pp}$ for the $3 \mathrm{mth}$ rate. In contrast, a positive change in real GDP by $1 \mathrm{pp}$ increases the prediction error on the interest rate curve by $0.04 \mathrm{pp}$. These results reflect that core inflation seems to drive the forecast error for longer-dated rates while economic growth is more relevant for forecasts of the shorter-dated part of the interest rate curve. The purified forecast error is highly correlated $(0.93)$ with the original time series and still exhibits the peaks for the period between 2015 and 2016 with financial markets caught surprised about the degree of curve flattening.

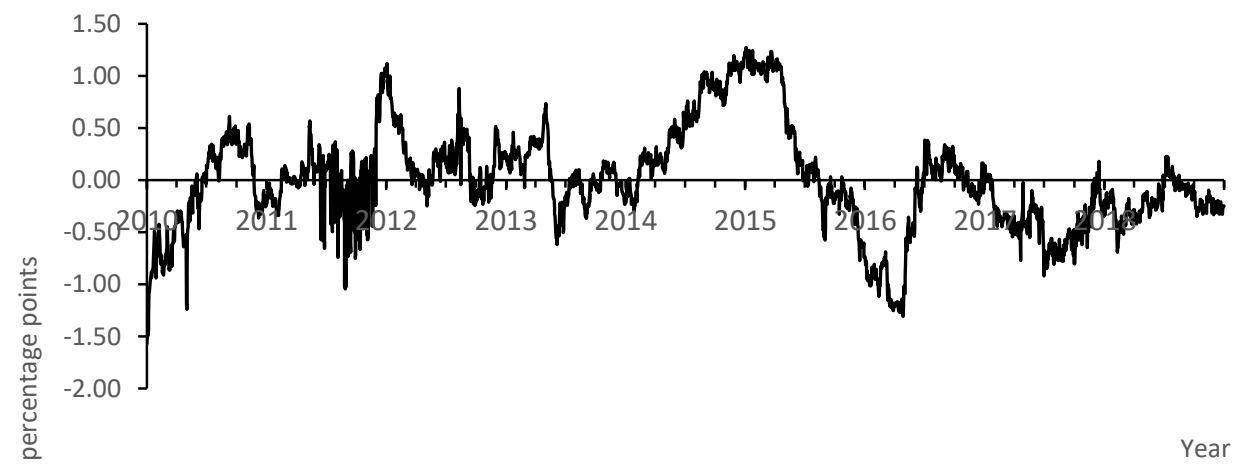

Figure 4. Macro purged yield curve error 


\subsection{Quantification of the Effect of Forward Guidance on the Prediction Error}

During the period of unconventional monetary policy, the ECB gradually strengthened their grip on the interest rate curve through an expanded monetary toolkit. The official introduction of FG on July $4^{\text {th }}, 2013$ adds to a series of new and non-standard monetary instruments that have impacted financial markets and corresponding forecasts. Not only does the actual start date of FG leave room for discussion, it is the plethora of newly introduced central bank measures and the corresponding communication policy that makes it inherently difficult to isolate and quantify the impact of FG on interest rate predictability. Hence, this section starts with a parsimonious definition of a dummy variable reflecting the official start of FG and widens the scope of analysis to include monetary policy control variables.

\subsubsection{Baseline Model without Control Variables}

Table 3 displays the results of regressing the purged error term on the FG dummy and a constant only. This represents a reduced form of eq. (4) without the vector of controls. Results of the baseline specification reveal that during the regime of FG starting July $4^{\text {th }} 2013$, the forecast error of interest rate levels (FE_1Y) has decreased (column 1) while the forecast error of the slope of the ( 3 months to 10 year) yield curve (FE_3M10Y) has increased (column 2).

Table 3. Baseline regression results - official FG regime

\begin{tabular}{lcccc}
\hline & FE_1Y & FE_3M10Y & FE_3M1Y & FE_1Y10Y \\
\hline const & $0.3694^{* * *}$ & $0.3105 * * *$ & $0.2583^{* * *}$ & $4.291^{* * *}$ \\
& $(0.0049)$ & $(0.0089)$ & $(0.0038)$ & $(0.0093)$ \\
FG_4_July_2013 & $-0.1889^{* * *}$ & $0.0990^{* * *}$ & $-0.1054^{* * *}$ & $0.0303^{* *}$ \\
& $(0.0062)$ & $(0.0114)$ & $(0.0048)$ & $(0.0119)$ \\
\hline Adj. R-squared & 0.2182 & 0.0221 & 0.127 & 0.002 \\
\hline
\end{tabular}

Note. FE stands for the purged forecast error measured for the 1yr forecast horizon. FE followed by one number represents a level forecast for the respective maturity. FE followed by two numbers represents a slope forecast for respective maturities.

Significance Levels:*1\%, ** 5\%, ***10\%.

Regarding the level forecasts, the coefficient of the FG dummy is highly significant and points to a reduction of the error term by $0.19 \mathrm{pp}$. This finding lends support to our initial hypothesis that this new communication tool helped financial market participants to more accurately predict future interest rates. The FG regime has obviously succeeded in reducing the perceived probability of unexpected rate hikes given the asymmetric risk profile for the interest rates at the ZLB. However, regarding the forecasts on the slope of the interest rate curve, results show an increase in the forecast error by $0.10 \mathrm{pp}$ (column 2). The decomposition of this observation into its two components, the forecast error of the $3 \mathrm{mth}$ OIS contract and the 10yr OIS contract, shows that FG leads to a reduction of the forecast error term for the shorter horizon (column 3) and a slight increase for the longer maturity (column 4). While monetary policy has succeeded in guiding market expectations of short-term maturities, the structural decline of the $10 \mathrm{yr}$ interest rate was not anticipated by financial markets participants. This finding indicates that the ECB's goal to suppress long-term refinancing conditions was achieved at the cost of surprising markets on the path of long-term yields.

\subsubsection{Baseline Model with Additional Control Variables}

To further refine the perspectives on the central bank regime under FG, this section introduces additional control variables that represent major monetary policy operations over the sample period as specified in the full form of eq. (4). The regression results are shown in Table 4. The control variables we included are the following: LTRO represents the unconditional long-term refinancing operations of the European Central Bank; ExcLiq is the liquidity provided by the central bank system; EAPP captures monthly asset purchases conducted by the ECB and TLTRO stands for the targeted long-term refinancing operations of the ECB.

Regarding the forecast error for the 1y1y OIS (FE_1Y), FG remains significant in narrowing the prediction error by $0.17 \mathrm{pp}$ (column 1). This represent a decline by two basis points as compared to the specification without control variables. The latter are all highly significant and the model improves to 0.29 . The intercept of the regression stands at $0.50 \mathrm{pp}$ which we interpret as the structural absolute prediction error if we account for both FG and other monetary policy actions. As this value is $0.15 \mathrm{pp}$ larger than the average of the absolute purged prediction error, we infer that the sum of monetary policy measures significantly compresses the interest rate forecast error. 
Table 4. Extended regression - official FG regime

\begin{tabular}{lcc}
\hline & FE_1Y & FE_3M10Y \\
\hline const & $0.4946^{* * * *}$ & $0.4565^{* * *}$ \\
& $(0.0117)$ & $(0.0218)$ \\
FG_4_July_2013 & $-0.1685^{* * *}$ & $0.1309 * * *$ \\
& $(0.0083)$ & $(0.0154)$ \\
LTRO & $-0.1685^{* * *}$ & $-0.1599^{* * *}$ \\
& $(0.0083)$ & $(0.0362)$ \\
ExcLiq & $0.1673^{* * *}$ & $-0.1265^{* * *}$ \\
& $(0.0100)$ & $(0.0187)$ \\
EAPP & $-2.0501 * * *$ & -0.1923 \\
& $(0.1425)$ & $(0.2647)$ \\
TLTRO & $-0.4858^{* * *}$ & $0.3132 * * *$ \\
& $(0.0470)$ & $(0.0874)$ \\
\hline Adj. R-squared & 0.293 & 0.089
\end{tabular}

Note. FE stands for the purged forecast error measured for the $1 \mathrm{yr}$ forecast horizon. FE followed by one number represents a level forecast for the respective maturity. FE followed by two numbers represents a slope forecast for respective maturities.

Significance Levels:*1\%, ** 5\%, ***10\%.

On the prediction error of the slope forecasts (FE_3M10Y), the fully specified baseline model suggests that FG increases the forecast error by $0.13 \mathrm{pp}$ yielding a model fit of 0.089 (column 2). This effect is stronger than for the slope forecast in isolation (by $+0.10 \mathrm{pp}$ ). Hence, the monetary control variables seem to have a dampening effect on the absolute error term, where FG is the main reason for markets underestimating the flattening of the interest rate curve. The intercept of $0.46 \mathrm{pp}$ reflects again the structural error term that markets exhibit in their forecasts for the slope of the interest rate curve.

\section{Robustness Tests}

This section considers different specifications of the baseline model and extends the analysis across different maturities. For the level forecast, we vary the maturity of the OIS contract to 3 months (FE_3M) and 10 years (FE_10Y). Regarding the slope of the yield curve, we analyze the slope between the $1 \mathrm{y}$ and the $3 \mathrm{mth}$ maturity (FE_3M1Y) and the 10y and 1y attachment points (FE_1Y10Y) (Note 9). To address the question whether the official start date of FG marks the unambiguous beginning of a new communication regime, we estimate the baseline regression with an alternative dummy variable that represents the key speech of Mario Draghi on July $26^{\text {th }}, 2012$, where he reiterates the ECB's willingness "to do whatever it takes" to preserve the euro.

\subsection{Prediction Error for the Level and Slope Forecast with Different Maturities}

We first purged the forecast errors as before (Note 10). As displayed in Table 5, we find that unconventional monetary policy has a higher overall explanatory power for interest level forecast at shorter maturities than for the long term. While the adjusted $\mathrm{R}^{2}$ indicates a model fit of 0.26 for the $3 \mathrm{mth}$ OIS contract, this statistic increases slightly to 0.293 for the $1 \mathrm{yr}$ OIS contract (as shown in Table 4, column 1) and eventually drops to 0.07 for the 10yr horizon (Table 5 Column 2). It is a common finding that central bank policies have a greater impact on the front-end of the interest rate curve than for longer maturities.

As a stark contrast to the baseline specification, FG leads to an increase of the absolute forecast error for the 10yr OIS contract (FE_10Y) by $0.16 \mathrm{pp}$ while the effect on the 3mth OIS contract (FE_3M) is rather insignificant in size. We infer that FG has fostered interest rate predictability for interest rates at shorter maturities but significantly decreased predictability at the long-end of the interest rate curve. The explanatory power of unconventional monetary policy on the absolute forecast error of the slope of the yield curve also declines with increasing maturity.

The model on the yield curve at the front-end indicates an adjusted $R^{2}$ of 0.23 for the $1 \mathrm{y}-3 \mathrm{mth}$ attachment points (FE_3M1Y), while variation in the forecast error of the 10y-1y slope (FE_1Y10Y) is explained to a lesser degree by monetary policy (adjusted $\mathrm{R}^{2}$ of 0.08 ). The positive effect of FG on the forecast error of the baseline model $(0.13 \mathrm{pp})$ stems solely from the long-end of the curve that points to an increase of the prediction error of $0.16 \mathrm{pp}$ as can be seen in Table 4 in combination with Table 5. These findings highlight that the source of the forecast error for the slope is the strong an unexpected decrease of longer-term maturities. 
Table 5. Regression regression results for extended set of maturities

\begin{tabular}{lcccc}
\hline & FE_3M & FE_10Y & FE_3M1Y & FE_1Y10Y \\
\hline const & $0.1497 * * *$ & $0.3685^{* * *}$ & $0.2790 * * *$ & $0.4400^{* * *}$ \\
& $(0.0088)$ & $(0.0228)$ & $(0.0069)$ & $(0.0201)$ \\
FG_4_July_2013 & $-0.0224 * * *$ & $0.1554 * * *$ & $-0.0968 * * *$ & $0.0390 * * *$ \\
& $(0.0062)$ & $(0.0161)$ & $(0.0048)$ & $(0.0142)$ \\
LTRO & $0.1471 * * *$ & $0.1873 * * *$ & $-0.1677 * * *$ & $-0.0739 * *$ \\
& $(0.0145)$ & $(0.0379)$ & $(0.0114)$ & $(0.0334)$ \\
ExcLiq & $0.0373^{* * *}$ & $-0.1914 * * *$ & $0.0413 * * *$ & $-0.1766 * * *$ \\
& $(0.0075)$ & $(0.0195)$ & $(0.0059)$ & $(0.0172)$ \\
EAPP & $-1.1611^{* * *}$ & $-1.0842^{* * *}$ & 0.1016 & $0.4813 * *$ \\
& $(0.1063)$ & $(0.2770)$ & $(0.0834)$ & $(0.2442)$ \\
TLTRO & $-0.3968 * * *$ & $0.3767 * * *$ & $-0.2546 * * *$ & $0.6118^{* * *}$ \\
& $(0.0351)$ & $(0.0915)$ & $(0.0275)$ & $(0.0806)$ \\
\hline Adj. R-squared & 0.262 & 0.066 & 0.225 & 0.080 \\
\hline
\end{tabular}

Note. FE stands for the purged forecast error measured for the 1yr forecast horizon. FE followed by one number represents a level forecast for the respective maturity. FE followed by two numbers represents a slope forecast for respective maturities.

Significance Levels:*1\%, ** 5\%, ***10\%.

\subsection{Alternative Starting Date of FG}

As displayed in Table 6, with Draghi's "whatever it takes speech" as the alternative beginning of FG (FG_26_July_2012), we can observe an increase of the model fit to 0.36 for the $1 \mathrm{y}$ maturity. The forecast error of the level (FE_1Y) decreases to - $0.21 \mathrm{pp}$ compared to a negative impact of $-0.17 \mathrm{pp}$ (Table 4) in the baseline model. Results for the forecast of the slope of the yield curve show similar characteristics with a highly significant coefficient which indicates that FG leads to a widening of the prediction error by $0.12 \mathrm{pp}$ (compared to $0.13 \mathrm{pp}$ in the baseline). As can be seen from the columns 3 through 6 of Table 6 , the results as well as the overall fit for the alternative maturities also improves. Hence, the ECB's the announcement of unconditional support of the euro within its mandate marks a significant event that has helped to improve interest rate predictability.

Table 6. Extended regression results with altenative FG period

\begin{tabular}{lcccccc}
\hline & FE_1Y & FE_3M10Y & FE_3M & FE_10Y & FE_3M1Y & FE_1Y10Y \\
\hline const & $0.4379 * * *$ & $0.5115^{* * *}$ & $0.1537 * * *$ & $0.4503 * * *$ & $0.2444 * * *$ & $0.4547^{* * *}$ \\
& $(0.0102)$ & $(0.0200)$ & $(0.0078)$ & $(0.0211)$ & $(0.0061)$ & $(0.0184)$ \\
FG_26_July_2012 & $-0.2119 * * *$ & $0.1149 * * *$ & $-0.0806 * * *$ & $0.0609 * * *$ & $-0.1124 * * *$ & $0.0417 * * *$ \\
& $(0.0074)$ & $(0.0145)$ & $(0.0056)$ & $(0.0153)$ & $(0.0044)$ & $(0.0133)$ \\
LTRO & $-0.0767 * * *$ & $-0.2870^{* * *}$ & $0.2007 * * *$ & $0.0761 * *$ & $-0.0593 * * *$ & $-0.1157 * * *$ \\
& $(0.0185)$ & $(0.0362)$ & $(0.0141)$ & $(0.0383)$ & $(0.0110)$ & $(0.0333)$ \\
ExcLiq & $0.1263 * * *$ & $-0.0999 * * *$ & $0.0262 * * *$ & $-0.1680^{* * *}$ & $0.0187 * * *$ & $-0.1679 * * *$ \\
& $(0.0095)$ & $(0.0187)$ & $(0.0073)$ & $(0.0197)$ & $(0.0057)$ & $(0.0172)$ \\
EAPP & $-1.6096^{* * *}$ & -0.1870 & $-0.7358^{* * *}$ & $-0.5494 *$ & $0.2898 * * *$ & $0.4313 *$ \\
& $(0.1363)$ & $(0.2673)$ & $(0.1042)$ & $(0.2826)$ & $(0.0814)$ & $(0.2462)$ \\
TLTRO & $-0.4497 * * *$ & $0.3394 * * *$ & $-0.3348 * * *$ & $0.4905 * * *$ & $-0.2440 * * *$ & $0.6116^{* * *}$ \\
& $(0.0444)$ & $(0.0871)$ & $(0.0340)$ & $(0.0921)$ & $(0.0265)$ & $(0.0802)$ \\
\hline Adj. R-squared & 0.364 & 0.087 & 0.302 & 0.044 & 0.275 & 0.081 \\
\hline
\end{tabular}

Note. FE stands for the purged forecast error measured for the 1yr forecast horizon. FE followed by one number represents a level forecast for the respective maturity. FE followed by two numbers represents a slope forecast for respective maturities.

Significance Levels:*1\%, ** 5\%,***10\%.

\section{Conclusion}

This study analyzes the impact of ECB's forward guidance on the forecast error of financial markets participants regarding the interest rate level and the slope of the yield curve. To account for external factors other than the exogenous quality of interest rate predictions, we purge the error term of macroeconomic and financial variables and then control the absolute, purged forecast error for instances of unconventional monetary policy. 
We find that the introduction of FG by the ECB on July $4^{\text {th }}, 2013$ leads to a decline in the prediction error of the interest rate level by $0.17 \mathrm{pp}$ for the $1 \mathrm{yr}$ maturity for the $1 \mathrm{yr}$ forecasting horizon. While the effect is negligible for $3 \mathrm{mth}$ maturities, the forecasting error of interest rates of $10 \mathrm{yr}$ increases through the introduction of FG by $0.16 \mathrm{pp}$ on the back of the decline of the 10yr interest rate which caught markets by surprise. Hence, the ECB has succeeded in lowering long-term refinancing conditions at the price of lower interest rate predictability for longer dated maturities during the time of FG. This finding also manifests itself in the results for the prediction error of the slope of the interest rate curve. Measured as the difference between the $10 \mathrm{yr}$ and the $3 \mathrm{mth}$ maturities, forecasts of the interest rate curve become less accurate through the introduction of FG and increase by $0.13 \mathrm{pp}$ on an absolute basis on the back of the unanticipated fall of the 10yr rate. We further find that a different specification of FG including the "whatever it takes" speech by Mario Draghi results in an even stronger effect than the ECB's official announcement date. While the accuracy of the predictions on the interest rate level improve by two additional basis points, the forecasts on the slope of the yield curve worsen by another two basis points.

Overall, the ECB's communication policy has strong and observable effects on the forecast error of market participants. The fact that FG leads to an improved predictability for shorter maturities also implies a partial stabilization effect on financial markets. Further, if financial market participants themselves observe that FG has become a significant tool for steering interest rates further out on the maturity spectrum, the credibility of monetary policy and thus its effectiveness improves. For longer maturities, however, signals of the ECB have not been accurately reflected in the forecasts of financial market participants which leaves room for improved communication (and understanding) going forward.

\section{References}

Andersson, M., \& Hofmann, B. (2009). Gauging the effectiveness of quantitative forward guidance: Evidence from three inflation targeters. European Central Bank, Working Paper Series, no. 1098.

Andrade. P., \& Ferroni, F. (2016). Delphic and Odyssean monetary policy shocks: Evidence from the euro area. School of Economics University of Surrey Discussion Papers, no. 1216.

Becker, T., \& Smith, A. L. (2015). Has forward guidance been effective?. Federal Reserve Bank of Kansas City, Economic Review, 100(3), 57-78.

Campbell, J. R., Evans, C. L., Fisher, J. D. M., \& Justiniano, A. (2012). Macroeconomic effects of Federal Reserve forward guidance. Brookings Papers on Economic Activity, 1-54. https://doi.org/10.1353/eca.2012.0004

Del Negro, M., Giannoni, M., \& Patterson, C. (2012). The forward guidance puzzle. Federal Reserve Bank of New York, Staff Reports, October 2012, no. 574. https://doi.org/10.2139/ssrn.2163750

Draghi, D. (2012). Speech by Mario Draghi, President of the European Central Bank at the Global Investment Conference in London 26 July 2012. Retrieved from: https://www.ecb.europa.eu/press/key/date/2012/html/sp120726.en.html

Draghi, M. (2013). Introductory statement to the press conference (with Q\&A). Retrieved from https://www.ecb.europa.eu/press/pressconf/2013/html/is130704.en.html

Draghi, M. (2014). Introductory statement to the press conference (with Q\&A). Retrieved from https://www.ecb.europa.eu/press/pressconf/2014/html/is140306.en.html

European Central Bank. (2014). The ECB's Forward Guidance. Monthly Bulletin, 4, 65-73.

Fendel, R., Neugebauer, F., \& Niederhagen, N. (2017). A Note on the Reactions of Real Yields to Different Types of Forward Guidance in the US. Economics Bulletin, 37(4), 2703-2710.

Goodhart, C., \& Lim, W. B. (2011). Interest rate forecasts: A pathology. International Journal of Central Banking, 7(2),135-171.

Hatzius, J., Hooper. P., Mishkin, F., Schoenholtz, K. L., \& Watson, M. (2010). Financial conditions indexes: A fresh look after the financial crisis. U.S. Monetary Policy Forum (Chicago: Chicago Booth Initiative on Global Markets, 2010), 3-59. https://doi.org/10.3386/w16150

Hubert, P., \& Labondance, F. (2018). The effect of ECB forward guidance on the term structure of interest rates. International Journal of Central Banking, 14(5), 193-222.

Kool, C. J. M., \& Thornton, D. L. (2015). How effective is central bank forward guidance? Federal Reserve Bank of St. Louis Review, 97(4), 303-22. https://doi.org/10.20955/r.2015.303-22 
Krippner, L. (2013). Measuring the stance of monetary policy in zero lower bound environments. Economics Letters, 118(1), 135-38. https://doi.org/10.1016/j.econlet.2012.10.011

Krippner, L. (2014). Measuring the stance of monetary policy in conventional and unconventional environments. Working Paper No. 6/2014, Centre for Applied Macroeconomic Analysis. https://doi.org/10.2139/ssrn.2381654

Kuttner, K. (2001). Monetary policy surprises and interest rates: Evidence from the Fed funds futures market. Journal of Monetary Economics, 47(3), 523-44. https://doi.org/10.1016/S0304-3932(01)00055-1

Mincer, J., \& Zarnowitz, V. (1969). The evaluation of economic forecasts. In J. Mincer (Ed.), Economic Forecasts and Expectation (pp. 3-46). New York: Columbia University Press.

Schrimpf, A., \& Sushko, V. (2019). Beyond LIBOR: a primer on the new benchmark rates. BIS Quarterly Review, 29-52.

\section{Notes}

Note 1. The Bank of Japan has introduced this type of macro-conditional FG in 1999.

Note 2. The Bank of England has introduced goal-based FG in 2013 with explicit reference to unemployment numbers.

Note 3. The Federal Reserve has referred to such calendar-based FG in 2011.

Note 4. For an analysis of different types of FG with respect to the Fed, see Fendel et al. (2017).

Note 5. The loss function represents the absolute and squared deviation of the forecast from realized interest rates.

Note 6. Data for the OIS is measured end of day and data for the EURIBOR is determined by a fixing once a day at 11 am UK time.

Note 7. Banks have manipulated quoted interest rates for financial gain as the EURIBOR has been the reference rate for numerous financial contracts.

Note 8 . The control variables are represented by their actual volume and not as dummy variables.

Note 9. We do not consider interest rate forecasts greater than one year given increasing impact of other external factors on the interest rate predictability.

Note 10. For the sake of brevity, we do not report the results explicitly, but they are available upon request. As before, almost all chosen controls are statistically significant.

\section{Copyrights}

Copyright for this article is retained by the author(s), with first publication rights granted to the journal.

This is an open-access article distributed under the terms and conditions of the Creative Commons Attribution license (http://creativecommons.org/licenses/by/4.0/). 